\title{
DIREITOS FUNDAMENTAIS SOCIAIS, ORÇAMENTO PÚBLICO E RESERVA DO POSSÍVEL: O DEVER DE PROGRESSIVIDADE NOS GASTOS PÚBLICOS
}

\section{FUNDAMENTAL SOCIAL RIGHTS, PUBLIC BUDGET AND POSSIBLE RESERVE: THE PROGRESSIVITY DUTH IN PUBLIC SPENDING}

\author{
Emerson Affonso da Costa Moura \\ Professor Assistente da Universidade Federal de Juiz de Fora. Doutorando pela \\ Universidade do Estado do Rio de Janeiro com bolsa científica \\ PROQUALI/PROGEPE/UFJF. E-mail: emersonacmoura@yahoo.com.br
}

Jamir Calili Ribeiro

Doutor em Direito pela Pontifícia Universidade Católica (PUC-MG). Professor Adjunto da Universidade Federal de Juiz de Fora (UFJF). E-mail: jcalili@ hotmail.com

Recebido em: 18/10/2016

Aprovado em: 19/12/2016

Doi: $10.5585 /$ rdb.v16i7.510

RESUMO: A vinculação do orçamento público à concretização dos direitos fundamentais sociais de forma que há não apenas um dever de promoção pelos poderes públicos do núcleo essencial, mas um dever de progressividade nos gastos públicos de forma a garantir a realização de tais bens e valores é o tema posto à debate. Para tanto, analisa-se a efetividade dos direitos sociais, a regressividade do sistema fiscal brasileiro, os efeitos do gasto regressivo na consecução dos direitos fundamentais e o papel do orçamento na promoção dos direitos sociais e a sua correlação com reserva do possível.

Palavras-chave: Direitos Sociais; Orçamento; Gastos Públicos; Progressividade; Reserva do Possível

ABSTRACT: Linking the public budget to the achievement of fundamental social rights so that there is not only a duty to promote the public authorities of the essential core, but a duty of progressivity in public spending to ensure the realization of such assets and values is the theme put to debate. Therefore, we analyze the effectiveness of social rights, the regressive nature of the Brazilian tax system, the effects of regressive spent on achieving the fundamental rights and the role of the budget in the promotion of social rights and their correlation with reservation possible.

Keywords: Social Rights; Budget; Public spending; progressivity; Reserve Possible

SUMÁRIO: Introdução; 1. Os direitos fundamentais sociais e o dever de atuação estatal; 2. A regressividade do sistema fiscal brasileiro; 3. Gasto público regressivo e direitos sociais; 4. Orçamento, direitos sociais e reserva do possível; Conclusão; Referências. 


\section{INTRODUÇÃO}

A destinação dada pelos governos aos seus recursos é tema central de qualquer teoria que almeje verificar o alcance da justiça fiscal e tributária ou, de forma ampla, da justiça social. Se de um lado os recursos fiscais são indispensáveis à execução das funções estatais, devendo, sob a égide do Estado Democrático de Direito, serem cobrados de maneira progressiva e em relação à capacidade contributiva de cada um, por outro a "justiça tributária não pode ser determinada sem que se examine o destino que o governo dá a seus recursos", pois a justiça "está essencialmente ligada aos resultados" (NAGEL e MURPHY, 2005, p.20).

Além da forma imprópria para arrecadação dos recursos, a regressividade do sistema pode ser agravada com o retorno social inadequado do uso dos recursos públicos, quando a apropriação dos recursos arrecadados é feita por grupo social diferente daqueles grupos que menos possuem capacidade contributiva. Tal gasto público é caracterizado como um gasto regressivo, na medida em que reforça o caráter regressivo do sistema tributário e não se coaduna com os objetivos expressos no artigo $3^{\circ}$ do texto constitucional de construção de uma sociedade justa, extinção da pobreza, promoção do desenvolvimento nacional e redução das desigualdades.

O debate público a respeito dos limites e necessidade de atuação do Estado impõe que se investigue a origem e destinos dos recursos de forma sistemática, tendo em mente que o gasto público justifica o tributo e vice versa. A fim de compreender os mecanismos estatais para garantia de justiça social, é necessário que "o perfil dos gastos públicos, e não apenas da arrecadação, seja objeto de discussão com a sociedade, dado que a questão tributária é parte de uma gestão fiscal mais ampla" (BRASIL, 2011).

A importância do estudo sistêmico das finanças públicas também se justifica em razão de, nas palavras de Ricardo Lobo Torres (2009, p.4), "boa parte dos problemas das finanças atuais, no Brasil e no estrangeiro, veio do corte observado entre Direito Tributário e Direito Financeiro, que conduziu à irresponsabilidade fiscal e à própria crise fiscal que desestruturou o Estado de bem-estar social". Como se observa da realidade, principalmente nos tempos atuais de restrições fiscais, crise econômica e queda de arrecadação, as demandas sociais para prestação de bens e serviços pelo Estado por vezes extrapolam os limites dos recursos estatais, e o orçamento é a peça em que os conflitos distributivos afloram.

Com o crescente processo de judicialização das questões sociais e políticas, em especial, no que tange as demandas de concretização dos direitos sociais pelo Poder Judiciário, o oferecimento das prestações necessárias à fruição destes direitos fundamentais conduz ao questionamento acerca de que em qual medida pode o Estado-Juiz determinar o dispêndio de recursos sem observância da programação orçamentária e de que forma estão obrigados os Poderes Públicos a concretização de tais prestações.

Assim, o que se pretende neste artigo é verificar em que medida há uma vinculação do orçamento público à concretização dos direitos fundamentais sociais de forma que há não apenas um dever de promoção do núcleo essencial, mas refletindo sobre o caráter deontológico dos objetivos constitucionais que há um dever de progressividade não só como mandamento de arquitetura do sistema de arrecadação tributária mas também do sistema de gastos públicos.

Para isso inicia-se com uma discussão acerca dos deveres dos poderes públicos acerca dos direitos sociais, a saber, em que medida a superação do baixo grau de efetividade das normas constitucionais veiculadoras destes direitos fundamentais impõe o desafio à literatura jurídica em definir o conteúdo de concretização pelos poderes constituídos e, portanto, as prestações exigíveis pelo cidadão.

Após verifica-se a regressividade do sistema fiscal brasileiro, apontando a necessidade de análise sistemática do sistema de arrecadação e gasto público, a regressividade do sistema tributário e os dados nefastos da distribuição de renda no Brasil. Para dar mais concretude ao debate, aponta-se os benefícios fiscais e os gastos compensatórios, p. ex. o bolsa família, como 
práticas orçamentárias sujeitas ao controle administrativo e judiciário de sua progressividade ou regressividade. Se tais concessões orçamentárias não são compreendidas de maneira sistêmica, os efeitos do ponto de vista de justiça social podem ser anulados.

Em seguida, são descritas as teorias econômicas e sociológicas que evidenciam as consequências prejudiciais do gasto regressivo à consecução dos direitos fundamentais. Ademais, demonstra-se que, além de normas constitucionais, o legislador pátrio vem realizando esforço no sentido de positivar regras que direcionam para o afastamento de tais gastos.

Por fim, discute-se em que medida a alegada reserva do possível com a suposta falta ou limitação de recursos financeiro no orçamento público para a concretização dos direitos sociais pode inibir o dever estatal de promoção de tais direitos fundamentais ou significa um espaço de maximização da realização de tais valores sociais.

Tem-se como hipótese inicial, que a justiça na arrecadação e gasto público aflora quando pautada pelo alcance e realização de direitos sociais. Tendo em vista a escassez de recursos disponíveis ao Estado, os gastos regressivos impossibilitam o alcance desses direitos fundamentais e afrontam os valores democráticos, não encontrando legitimidade no Estado Democrático de Direito.

Neste sentido, embora não possa se sustentar um dever de realização plena dos direitos fundamentais sociais, que devem ser realizados em seu núcleo essencial, todavia, pode se afirmar que o orçamento enquanto peça financeira que programa os dispêndios para a concretização dos bens e valores constitucionais deve ser progressivo na busca pela ampliação da sua respectiva realização.

\section{OS DIREITOS FUNDAMENTAIS SOCIAIS E O DEVER DE ATUAÇÃO ESTATAL}

O Estado Constitucional de Direito é marcado além da submissão dos poderes públicos à sua produção legislativa pelo reconhecimento da força normativa da Constituição, que ao revés de sujeitar a concretização de seus preceitos às forças políticas vigentes adquire o status de norma jurídica que impõe obrigações jurídicas e, portanto, limites e deveres de atuação para o Estado (HESSE, 1991, p. 14).

$\mathrm{Na}$ experiência constitucional brasileira antes restrita a Constituições garantistas que tutelavam as liberdades formais como repositórios de promessas vagas o fenômeno ocorre com a promulgação de uma Constituição dirigente voltada à promoção social e pela crescente preocupação doutrinária com a aplicabilidade direta e imediata de seus preceitos. (BARROSO, 2003, p. 61).

Por efeito, interrompe-se, portanto, o ciclo inicial de baixa normatividade das disposições que veiculavam os direitos fundamentais, em especial, das normas que declaravam os direitos sociais, antes remetidas à esfera programática de meras linhas diretoras aos poderes públicos e, tidas como dotadas de eficácia limitada, sujeitas à discricionariedade do Estado quanto as prestações necessárias à sua realização. (BONAVIDES, 2003, p. 564-565).

Os direitos fundamentais enquanto veiculado por normas constitucionais gozam de exequibilidade plena, permitindo sejam os bens e interesses que tutelam exigíveis perante o Estado (BARROSO, 2006, p. 284), resta, entretanto, delimitar o conteúdo que integra as prestações passíveis de ser pleiteadas pelo jurisdicionado e, por efeito, o que compete aos demais poderes realizarem.

Neste giro, há novo deslocamento do eixo da questão, que antes gravitava em torno da aptidão para a produção dos efeitos jurídicos passa a orbitar sobre quais efeitos jurídicos podem ser produzidos, de forma a identificar as posições jurídicas que seus titulares estão investidos e, portanto, quais prestações podem ser exigidas dos poderes públicos, que passam a não se escusar do oferecimento. 
A investigação transpõe-se, portanto, do plano da eficácia para a efetividade com o objetivo de viabilizar a sua força operativa no mundo dos fatos. Isto impõe a definição da natureza das normas constitucionais que veiculam os direitos fundamentais, e assim, delimitar o conteúdo de sua exigibilidade pelos seus titulares, o que não se apresenta de modo uníssono na doutrina.

Destaca-se para análise em específico os direitos sociais visto o caráter eminentemente prestacional, que impõe para a sua concretização o oferecimento de prestações necessárias à fruição pelos seus titulares, sem desconsiderar que todos os direitos fundamentais impõe a alocação de recursos pelos poderes públicos para garantir o exercício da liberdade individual (HOLMES; SUSTEIN, 1999).

Inicialmente, sob o influxo do socialismo científico e do constitucionalismo social erige a tese do primado dos direitos sociais. O monopólio dos direitos de liberdade considerados eminentemente burgueses é rompido incorporando a lei fundamental algumas das exigências sociais, econômicas e culturais do proletariado em ascensão, redimensionando o homemindivíduo pelo homem-total no plano econômico, social e cultural (GOMES, 1982, p. 371).

Os direitos sociais são tidos jusfundamentais e superiores em relação aos postulados liberais (PASUKANIS, 1989, p. 88-89) e a sua aplicabilidade independe de intermediação legislativa, permitindo de plano a definição de direitos a prestações originárias, sendo orientada pela atribuição da máxima eficácia possível às suas normas definidoras. (BARROSO, 2003, p. 272 e 374$)$.

Não obstante, o recuo do socialismo como organização político-econômica e o colapso Estado de Bem-Estar Social retiram a força desta matriz teórica. A insuficiência dos recursos, a má prestação dos serviços pelo ente estatal e a falta de legitimidade da teoria dentre outras razões demonstraram a inviabilidade da manutenção de uma teoria voltada à máxima eficácia e prevalência apriorística dos direitos sociais.

Ascende com o declínio do Estado Providência e tendo por fundamento as declarações e pactos internacionais, a tese da indivisibilidade dos direitos humanos. (BOBBIO, 2004, p. 5-6) Segundo a construção, os direitos sociais se identificam como uma segunda geração ou ciclo dos direitos fundamentais, porém, sua exigibilidade se sujeita a certos parâmetros.

Com alicerce no Pacto Internacional dos Direitos Econômicos, Sociais e Culturais, esta doutrina distingue os direitos civis e políticos dotados de autoaplicabilidade e, portanto, assegurados de forma imediata pelo Estado, dos direitos sociais que se sujeitam a realização progressiva pelos poderes públicos até o máximo dos recursos disponíveis. (PIOVESAN, 1997, p. 195-199).

Isto decorria da impossibilidade de aplicabilidade integral dos direitos sociais em um curto período de tempo, diante de sua demanda por recursos econômicos em um contexto de escassez de recursos e, desta feita, a necessidade de escolhas dramáticas, que imporiam a adoção de medidas econômicas e técnicas, isoladas ou em conjunto pelo Estado em cooperação internacional de forma graduada.

Neste ponto, a tese sustentada encontra alguns impasses, em especial, a restrição da eficácia dos direitos sociais, vistos como fundamentais, à intermediação do poderes públicos, o que resultaria na banalização da temática dos direitos da liberdade sem fortalecimento dos direitos da justiça e a consideração de que apenas os direitos sociais demandam custos econômicos para a sua realização. (TORRES, 2009, p. 52-53)

Ademais importaria na violação dos direitos civis e políticos, cujo exercício pressupõe a garantia mínima do bem-estar, que envolve a realização de condições econômicas e sociais básicas. Condicionar a concretização dos direitos sociais à discricionariedade administrativa e conformação legislativa seria permitir que uma geração dependesse, da "vontade" dos poderes públicos para poder exercer substancialmente às liberdades e o direito ao voto. 
Em razão disto, é recorrente a criação de balizas pela literatura jurídica, que pretende definir uma posição entre os extremos apresentados - a exigibilidade plena e imediata de todos direitos sociais ou a dependência destes direitos fundamentais para sua concretização dos poderes constituídos - capaz de delimitar um núcleo mínimo exigível de prestações positivas dos direitos sociais.

Certa perspectiva, parte da premissa de que as normas constitucionais conformam de modo distinto os postulados ou princípios fundamentais que orientam a ordem econômica e social. Enquanto algumas disposições possuem a estrutura lógico-normativa de regras definindo direitos outras ordenam interesses com um caráter prospectivo e, portanto, possuem natureza de princípios. (SARLET, 2004, p. 275-350).

Desta forma, as normas programáticas indicam os fins sociais almejados, através de proposições diretivas imediatamente observáveis e projeções de comportamento de efetivação progressiva inserto no universo das possibilidades do Estado e da Sociedade. Embora não gerem direitos a prestações para os seus titulares, produzem consequências desde o início de sua vigência. (BARROSO, 2003, p. 156).

Em outra vertente, as normas constitucionais definidoras de direito veiculam bens e interesses sociais conceitualmente qualificáveis como direitos públicos subjetivos, que são pronta e diretamente exigíveis pelos seus titulares aos poderes públicos. Estas regras, todavia, produziriam efeitos de ordens variadas investindo os jurisdicionados em posições jurídicas diferentes.

Dadas normas permitiriam que situações fossem prontamente desfrutáveis dependentes apenas da abstenção pelos os poderes públicos, outras ensejariam a prática de determinadas prestações positivas pelo Estado e certas contemplariam interesses que dependeriam da edição de norma infraconstitucional integradora, como o direito de greve (Art. 9. ${ }^{\circ}$ da CF/1988), que depende da abstenção do Estado de reprimir ou punir os seus titulares;

Note, porém, que todos os direitos para alcançar a sua efetividade dependem da prática de prestações positivas e negativas pelos poderes públicos. Este dever estatal na concretização dos direitos sociais pode ser disposto em níveis de obrigações estatais, identificadas desde o dever de respeitar e proteger, até assegurar e promover o acesso aos bens sociais. (ABRAMOVICH, 2003, p. 139-141).

Outra tese busca a afirmação dos direitos sociais através da redefinição de sua jusfundamentalidade. (TORRE, 2008, p. 53-81) Com esteio nas teorias do direito e da filosofia política de JOHN RALWS e de JURGEN HABERMAS, os direitos sociais seriam fundamentais apenas quanto o seu núcleo essencial, ou seja, as condições mínimas ou indispensáveis para uma existência humana digna.

Por consequência, na realização dos direitos sociais são definidas duas medidas que confluem para o equilíbrio entre liberdade e justiça, resultantes da impossibilidade de se promover os bens e interesses sociais em toda sua extensão e a necessidade de garantir a sua efetividade ao menos em profundidade na sua dimensão mínima, em especial, em Estados com grandes desigualdades sociais.

Um vetor refere-se ao dever de maximização pelo Estado do conteúdo dos direitos sociais que integra o mínimo existencial - núcleo irredutível e indisponível, insuscetível de ponderação e restrições pelo legislador - impondo a sua realização na dimensão máxima através da promoção de prestações negativas e positivas, insuscetíveis de restrições pelos poderes públicos e plenamente garantidos pela jurisdição.

Outro diz respeito ao dever de otimização no que excede este conjunto básico realizável também por políticas públicas, mas exigíveis originariamente por via do exercício da cidadania reivindicatória, e de forma subsidiária pelo Poder Judiciário, observada as reservas de distintas ordens a que estão sujeitos. Isto porque, tal qual há limites mínimos devem haver bordas que exteriorizem limites máximos. 
De tal sorte que, é possível extrair dentro de um universo de prestações capazes de promover os bens e interesses de cada direito social, aquelas conexas a preservação da liberdade, que serão exigíveis independente de reserva orçamentária ou intermediação do legislador e outras ligadas à justiça social dependentes de uma otimização progressiva e dos recursos disponíveis.

É o que ocorreria, por exemplo, com a educação fundamental e a medicina preventiva e de urgência que correspondendo respectivamente ao núcleo essencial do direito à educação e saúde, poderiam ser exigidas pelos indivíduos que precisem perante o Poder Judiciário sem restrições. Já o ensino superior e o médio e a medicina curativa exorbitariam este conteúdo, razão pelo qual, dependeriam da progressiva realização pelos poderes públicos.

Em sentido semelhante, parte da doutrina propõe a ampliação da fundamentalidade material dos direitos sociais, de forma a compreender não somente as condições mínimas para uma existência humana digna, mas também as condições necessárias para que cada indivíduo possa exercer substancialmente a autonomia privada, mas igualmente, a sua autonomia pública. (SOUZA NeTO, 2008, P. 535-538.)

Tendo em vista, a construção de um modelo cooperativo no contexto democrático, os direitos sociais fundamentais englobariam também a igualdade de meios para agir, de forma a garantir a igual possibilidade de realização de um projeto de vida adequado e de participação do processo de formação da vontade coletiva, de forma que a exigibilidade plena e imediata abrangeria o ensino médio que permite a escolha livre da profissão.

Neste sentido, as últimas teorias, tidas de forma correlata, viabilizam um ponto ideal entre a inegável impossibilidade de se declarar a jusfundamentalidade de todas as regras que veiculam bens e interesses sociais e a indiscutível inviabilidade de tornar-se exigível todas as prestações decorrentes dos direitos sociais, mas as condições mínimas para uma existência humana digna e pressupostos iniciais para a participação democrática.

Naquilo que exorbitar este microcosmo, os direitos sociais possuem exigibilidade mediata condicionada sua concretização à intermediação pelos poderes públicos, através das escolhas dramáticas realizadas, nos limites de sua esfera de conformação ou discricionariedade, em um contexto de multiplicidade de atribuições e escassez de recursos econômicos pelos agentes estatais.

Note, portanto, que se os direitos fundamentais sociais possuem tal núcleo de obrigatoriedade de cumprimento pelos poderes públicos isto irradia sob o orçamento público que é a peça onde irá concretizar de forma financeira as escolhas políticas fundamentais da sociedade e, portanto, deverá ser progressivo de forma a garantir a concretização dos direitos do cidadão.

\section{A REGRESSIVIDADE DO SISTEMA FISCAL BRASILEIRO}

O conceito de regressividade no gasto público e suas aplicações devem ser investigados a partir da doutrina jurídica e das teorias sociológica e econômica, ciências estas que convergem para um entendimento comum a respeito do gasto público mal aplicado - aquele não direcionado às pessoas que de fato precisam - e suas consequências prejudiciais ao desenvolvimento social.

Parte-se de uma análise da arrecadação e gasto público de forma sistemática e sob a ótica dos limites para realização de direitos fundamentais. O texto está pautado nos objetivos estabelecidos no art. $3^{\circ}$ do texto constitucional, no mandamento constitucional da justa distribuição do ônus (princípio da capacidade contributiva, art. $145, \S 1^{\circ}$ da Constituição Federal) e benefícios da atuação do poder público, e no fato de que a desigualdade de renda verificada no país se deve, em grande medida, à falta de progressividade tanto do sistema tributário como do gasto público.

As investigações no direito financeiro devem ir além do formalismo e hermetismo comum na ciência jurídica das finanças, e realizar uma leitura embebida dos princípios constitucionais e democráticos, fazendo uso de uma análise jurídica das políticas públicas, as 
quais se manifestam principalmente por meio das escolhas públicas evidenciadas nas peças orçamentárias.

A classificação de um tributo como regressivo ocorre na medida em que "cresce a onerosidade relativa em razão inversa da capacidade contributiva do contribuinte" (GASSEN, 2009). O sistema tributário brasileiro tem como característica fática e jurídica a regressividade (FERRAZ; GODOI. SPAGNOL, 2014), principalmente em razão da base de tributação se concentrar sobre a produção e o consumo (tributos indiretos), pois a incidência de tais tributos se realiza sobre fatos que pouco dizem sobre a capacidade de pagamento dos indivíduos. Em razão disso, inviabilizam-se mecanismos de diferenciação de cargas tributárias em compasso com a capacidade de pagamento, exceto no caso das alíquotas seletivas (função da essencialidade do produto).

Conforme Observatório da Equidade do Conselho de Desenvolvimento Econômico e Social (BRASIL, 2011), as pessoas que ganhavam "até dois salários mínimos em 2004 gastaram $48,8 \%$ de sua renda no pagamento de tributos, já o peso da carga tributária para as famílias com renda superior a 30 salários mínimos correspondia a 26,3\%”. Ademais, a participação dos tributos indiretos corresponde a $47 \%$ da carga tributária total - nos países desenvolvidos aproximadamente $30 \%$ - enquanto os tributos sobre a renda e propriedade somam $25 \%$ do total (GIAMBIAGI e ALÉM, 2011, p. 254).

Não apenas devido à preponderância dos tributos indiretos, a má distribuição do encargo estatal também se deve a mecanismos inadequados em tributos diretos, notadamente o Imposto sobre a Renda ${ }^{1}$. Conforme descrito por Carlos Araújo Leonetti (2003, p. 185), há diversas regras atinentes ao Imposto sobre a Renda Pessoa Física que o limitam na sua eficácia como instrumento de justiça social, entre os quais o tratamento desigual a contribuintes em situação equivalente e a adoção de alíquotas pouco progressivas ${ }^{2}$.

Ainda em relação ao Imposto sobre a Renda, ressalta-se que o Brasil é um dos únicos países em que a distribuição de dividendos ainda não é tributada ${ }^{3}$ (CASTRO, 2014, p. 52), o que, aliado ao fenômeno crescente da "pejotização" de atividades profissionais, configura-se uma dos regras para a não progressividade da tributação sobre a renda. Para Fábio Ávila Castro, o

Brasil isenta totalmente a distribuição de lucros e dividendos de forma a evitar a bitributação do lucro empresarial. O fato é que o resto do mundo continua a fazer essa dupla tributação sem nenhum problema [...] porque reconhecem que

\footnotetext{
${ }^{1}$ A doutrina jurídica entende que o Imposto sobre a Renda se trata de imposto de caráter fiscal, ou seja, destinado a arrecadar receitas financeiras para os cofres públicos, sem viés de extrafiscalidade (sem finalidade regulatória ou de realizar determinada política econômica e social). Há que ressaltar a fragilidade na divisão entre tributos fiscais e tributos extrafiscais, tendo em vista que todo tributo arrecada receitas para o Estado e, de certa forma, intervém na propriedade alheia. Para Gassen (2012), a perspectiva extrafiscal tem a finalidade "também de legitimação do poder político, de legitimação da institucionalização da figura do Estado de uma ou outra forma". Ainda segundo o autor, "Nas escolhas acerca da matriz tributária sempre estará presente a dicotomia fiscal e extrafiscal como aqui abordada em um frágil e provisório equilíbrio." Segundo Castro (2011), “o direito tributário deve, do ponto de vista didático, ser fundido com o direito financeiro e dar muito mais ênfase à chamada extrafiscalidade do que a antiga dogmática permite".

${ }^{2}$ O livro de Carlos Araújo Leonetti foi publicado em 2003, quando havia apenas duas alíquotas para o Imposto sobre a Renda Pessoa Física. No entanto, ainda que tenham sido criadas mais duas alíquotas para o IRPF, é possível afirmar que a progressividade é inferior à maioria dos países em desenvolvimento e desenvolvidos, principalmente em razão da baixa alíquota máxima, conforme demonstrado na dissertação de Fábio Ávila de Castro (2014).

${ }^{3} \mathrm{O}$ governo federal tem apresentado propostas legislativas para se instituir a tributação de dividendos. Até o fechamento deste artigo, março de 2016, o governo Dilma não tinha obtido sucesso na instituição da obtenção de dividendos como fato gerador tributável.

${ }^{4}$ Pejotização é a denominação do fenômeno jurídico, utilizada principalmente no âmbito das regras do direito do trabalho, em que o trabalhador constitui pessoa jurídica, substituindo um típico contrato de trabalho por uma suposta relação de contrato entre empresas.
}

Revista de Direito Brasileira | São Paulo, SP | v. 16 | n. 7 | p. 225 - 241 | Jan./Abr. 2017 
os verdadeiros beneficiários dos rendimentos distribuídos são seus proprietários e sócios que nada mais são do que pessoas físicas (CASTRO, 2014, p. 92).

Como consequência, mas não somente em razão dos fatos acima descritos, observa-se que a distribuição desigual dos rendimentos no Brasil, que se afigura historicamente como uma das piores entre todos os países, vem se mantendo estável, conforme verificado em Medeiros et al (2015) para o período de 2006 a 2012. Os autores analisaram dados tributários provenientes da Declaração Anual de Ajuste do Imposto de Renda da Pessoa Física (DIRPF) e da Pesquisa Nacional por Amostra de Domícilios (PNAD) e encontraram evidências de que a desigualdade de renda no Brasil é mais alta do que se imaginava. Conforme esses mesmos dados, essa desigualdade permaneceu estável entre 2006 e 2012.

Além da forma imprópria para arrecadação dos recursos, a regressividade do sistema pode ser agravada com o retorno social inadequado do uso dos recursos públicos, quando a apropriação dos recursos arrecadados é feita por grupo social diferente daqueles grupos que menos possuem capacidade contributiva. Consideramos neste artigo que tal gasto público deve ser considerado como um gasto regressivo, na medida em que reforça o caráter regressivo do sistema tributário e não se coaduna com os objetivos expressos no texto constitucional de construção de uma sociedade justa, extinção da pobreza, promoção do desenvolvimento nacional e redução das desigualdades.

Isso vale, por exemplo, para os casos de benefícios fiscais concedidos pelo governo federal a pessoas com grande capacidade contributiva. Por benefícios fiscais entende-se aqui as exonerações tributárias, que são as isenções, as reduções de tributo e a remissão (BREYNER, 2016, p. 158). Segundo Frederico Breyner:

Os benefícios fiscais podem ser introduzidos como forma de simplificar a tributação, ou torná-la instrumento de indução pelo estímulo a condutas que, ao ver do Estado, os agentes econômicos não realizariam na ausência da exoneração.

Verificamos, contudo, que nem sempre essas normas, apesar de aparentemente buscarem um fundamento de validade, cumprem com a determinação de obediência da capacidade econômica e de progressividade do sistema tributário. (BREYNER, 2016, p. 175).

Bem, nesse sentido, é possível que os órgãos de controle administrativos e judiciários façam uma análise constitucional de sua validade, o que demanda permanente verificação de sua compatibilidade com as normas ali insculpidas.

Por outro lado, uma outra política orçamentária que pode ser um contraponto com o sistema tributário regressivo são os gastos públicos compensatórios, que acabam por se configurar em uma devolução (tax refund) ao recolhimento feito indevidamente por quem não possui capacidade contributiva.

Essa aplicação atual da análise sistemática na ciência das finanças é demonstrada por Misabel de Abreu Machado Derzi (2014), ao afirmar que determinados gastos públicos adquirem legitimidade na medida em que atenuam o caráter regressivo do sistema tributário. A autora afirma que os gastos do programa Bolsa Família são insusceptíveis de restrição, pois têm o caráter de "devolução de impostos a todos aqueles desprovidos de capacidade econômica que, no entanto, suportam-lhes o ônus que lhes são transferidos nos preços das mercadorias [...] que adquirem". Para Derzi,

"se a Constituição determina que os tributos sejam graduados de acordo com a capacidade econômica de cada um, é direito daqueles que pagam os impostos, 
sem qualquer disponibilidade econômica para isso, obter a devolução do montante injustamente transferido aos cofres públicos" (DERZI, 2014, p.49).

Assim, Misabel Derzi entende que determinados gastos públicos são não somente legítimos em razão dos propósitos, mas também se justificam pelo caráter principiológico do sistema tributário em si, em que se deve buscar divisão equânime do ônus de atuação estatal, assim como respeito ao mínimo existencial ${ }^{5}$ e do princípio da vedação ao confisco. Tais gastos atuariam como restituição de tributos, muitos dos quais sobre o consumo, e isso se torna mais notório quando se percebe que aos de menor renda não estão disponíveis mecanismos de tax refund, como ocorre em vários países (DERZI, 2014, p. 50).

A jurista vai além e afirma que o uso de recursos públicos como no programa Bolsa Família deveria se fundamentar, oficial e formalmente, na devolução de tributos "injustamente arrecadados dos mais carentes", pois, sendo de amplo conhecimento a regressividade do sistema, “(...) permanece o silêncio constrangedor em relação à questão tributária". Assim, a "aferição da regressividade do sistema tributário deveria ser a meta mínima, numericamente definida, com que os benefícios e programas assistenciais deveriam ser mensurados" (DERZI, 2014, p. 55).

Nestes casos, também, é preciso permanente verificação, analisando-se a juridicidade do gasto público retornado a quem não deveria, sobretudo em razão de que diversos desses gastos podem acabar beneficiando classes mais abastadas, como é o caso de empréstimos de dinheiro público com juros baixos para determinados setores.

\section{GASTO PÚBLICO REGRESSIVO E DIREITOS SOCIAIS}

A análise econômica e sociológica se esforça em entender as relações existentes entre o gasto público e outros valores buscados no ordenamento jurídico, entre os quais a redução da desigualdade de renda, a garantia de direitos individuais e coletivos. Há estudos (MEDEIROS e SOUZA, 2013; WORLD BANK, 2004; ROCHA e MATTOS, 2011, BARROS e FOGUEL, 2001) que apontam haver pouca eficiência na realização dos gastos públicos no Brasil, ou até mesmo a relação inversa entre capacidade econômica e apropriação dos gastos, de forma que tais gastos contribuem para aumentar a desigualdade de renda ou impedir que outros valores sejam alcançados.

Demonstra-se em Medeiros e Souza (2013) que o Estado contribui diretamente para uma grande fração da desigualdade de renda. Segundo os autores, entre os mecanismos redistributivos existentes, as transferências relacionadas a salários de servidores públicos e Previdência são muito concentrados e regressivos. Por outro lado, as transferências de assistência social carregam forte carga de progressividade e contribuem para reduzir as desigualdades.

Alguns autores da literatura econômica, ao se referir ao gasto público direcionado aos mais pobres, fazem uso da expressão "focalização" do gasto público, conforme mencionado por Fabiana Rocha e Enlinson Mattos (2011, p.11). Neste trabalho, os autores analisaram a relação existente entre gasto público e distribuição de renda nos estados da federação brasileira. Em outras palavras, tentam avaliar a "eficiência do gasto público em promover a melhor equalização da renda". O trabalho conclui por uma relação "positiva bastante expressiva" entre a percentagem de transferência na renda das famílias e as medidas de distribuição de renda, ou seja, que as transferências reduzem expressivamente a desigualdade. Quanto aos gastos com educação ${ }^{6}$, os gastos são negativa e estatisticamente associados com as medidas de desigualdade, de forma que

\footnotetext{
${ }^{5} \mathrm{O}$ respeito ao mínimo existencial se apresenta como o direito "às condições mínimas de existência humana digna que não pode ser objeto de incidência fiscal e que ainda exige prestações estatais positivas” (TORRES, 2013, p. 69).

${ }^{6}$ Os gastos públicos se referem aos efetuados pelos estados-membros da federação, os quais alocam os gastos de educação no ensino fundamental e básico em proporção muito acima da incorrida pela União, a qual destina elevado volume de recursos para o ensino superior.
}

Revista de Direito Brasileira | São Paulo, SP | v. 16 | n. 7 | p. 225 - 241 | Jan./Abr. 2017 
também contribuem para redução da desigualdade. Para os demais gastos públicos, os autores encontraram relação inversa, no sentido de que certos gastos públicos contribuem para aumentar as medidas de desigualdade utilizadas.

Ainda segundo Rocha e Mattos (2011), existem estudos internacionais que procuram medir a relação entre gastos públicos e distribuição de renda, em destaque estudo para países da OCDE que encontrou evidências de que "gasto público redistributivo (exceto pensões) e desempenho da educação, medido pelas notas do PISA, têm efeito significativo sobre a distribuição de renda".

Segundo Ricardo Paes de Barros e Miguel Nathan Foguel, em vista do volume de recursos públicos despendidos no Brasil, a "má focalização atual dos gastos sociais é a única razão pela qual esses gastos não são capazes de erradicar ou, ao menos, reduzir a pobreza de forma acentuada no País" (2001, p.106).

A teoria econômica em finanças públicas (BIDERMAN e AVARTE, 2004; GIAMBIAGI e ALÉM, 2011) sustenta que, em vista dos recursos em geral serem escassos, os princípios da especialidade e da focalização devem orientar o poder público na busca da satisfação dos interesses coletivos. A teoria por trás desses princípios afirma que os recursos são escassos e, em consequência, toda decisão de política pública consiste em escolhas de prioridade que resultam ao mesmo tempo na inclusão e exclusão de interesses.

A vertente jurídica que mais se aproxima desses conceitos da literatura corresponde à teoria da reserva do possível, cujo conteúdo informa que "a construção de direitos subjetivos à prestação material de serviços públicos pelo Estado está sujeita à condição da disponibilidade dos respectivos recursos" (SCAFF, 2005, p.89). O problema reside no fato de que a disponibilidade de recursos é condição para efetivação de direitos fundamentais, nos seguintes termos colocados pelo autor:

Como os direitos fundamentais sociais são, por definição, direitos a prestações, não é razoável que se aloquem todos os recursos públicos disponíveis para sua implementação. Mas é imprescindível que sejam disponibilizados recursos públicos bastantes e suficientes, de forma proporcional aos problemas encontrados e de forma progressiva no tempo, de modo a que as deficiências para o exercício das liberdades jurídicas seja sanado através do pleno exercício das liberdades reais (Robert Alexy), ou, por outras palavras, para o exercício pleno das capacidades de cada indivíduo ou coletividade de indivíduos (Amartya Sen) (SCAFF, 2005, p. 99).

A partir desse raciocínio, Fernando SCAFF afirma que, “a teoria da Reserva do Possível somente poderá ser invocada se houver comprovação de que os recursos arrecadados estão sendo disponibilizados de forma proporcional aos problemas encontrados [...]."

Para Regis Fernandes de Oliveira (2013, p.128), um dos pilares do direito pátrio e parâmetro para o legislador e executor de políticas é a redução de desigualdade, e o gasto público que não se atenta a esse contorno constitucional está marcado por grave mácula. Para o autor, o princípio constitucional da eficiência exige que o administrador público faça uma análise de custo benefício de cada gasto público, de forma a confirmar o melhor atendimento possível aos preceitos constitucionais.

Nesse sentido, segundo o autor "se a administração pública despende grande parte de seus recursos para o atendimento de áreas mais favorecidas da cidade, ou seja, em bairros nobres, não se pode dizer que o princípio foi atendido" (OLIVEIRA, 2013, p.128). Em resumo, trata-se de exigir o atendimento a um critério de razoabilidade por parte do legislador ou administrador público que, em outras palavras, diz-se do princípio da legitimidade dos gastos públicos. 
O princípio da legitimidade ${ }^{7}$ aplicado ao gasto público consiste em perquirir padrões morais e analisar se a decisão do poder público "partilhou, na exata medida, os ônus e bônus que correspondem aos membros da sociedade", isso a partir de situações concretas, "em que se fará um juízo de ponderação entre as necessidade públicas e os meios e recursos adequados para atendê-las" (NAGATA, 2011, p. 378).

O dispêndio em certas atividades é o que torna possível a realização de direitos fundamentais e, em verdade, a garantia de todos os direitos fundamentais dependem de recursos do Estado, ou seja, os direitos têm custos, inclusive direitos tão fundamentais quanto o direito à vida, o direito de ir e vir (HOLMES; SUSTEIN, 1999), pois mesmos direitos que não exigem uma prestação positiva por parte do Estado, ainda assim exigem que o Estado mantenha uma estrutura judiciária capaz de garantir tais direitos. Por isso Fernando Scaff (2010) afirma que "de nada adianta falarmos de direitos se não olharmos quanto de recursos financeiros o Estado estabeleceu para a realização daqueles direitos".

Tal raciocínio nos conduz a questionar se o inverso também é verdadeiro, ou seja, se o gasto público que não se destina ao atendimento de valores consagrados no ordenamento jurídico exclui a possibilidade de uma realização maior dos valores buscados pela sociedade. A limitação orçamentária que a realidade não esconde e as teorias comumente adotadas na jurisprudência indicam que os gastos públicos não legítimos, baseados em critérios não condizentes com os objetivos fundamentais da república, são antijurídicos e afastam a possibilidade de construção da dignidade humana e uma justiça distributiva.

A dificuldade consiste em afirmar categoricamente quais gastos atendem aos objetivos traçados pela Carta Magna, pois, ao se analisar a efetivação de critérios de justiça social, há "alto grau de incerteza empírica acerca das consequências econômicas das diversas opções que se apresentam, e é difícil desvincular as discordâncias sobre a justiça das discordâncias sobre o que poderá acontecer" (NAGEL e MURPHY, 2005).

\section{ORÇAMENTO, DIREITOS SOCIAIS E RESERVA DO POSSÍVEL}

No que tange a concretização dos direitos fundamentais sociais, em especial, através do controle pelo Poder Judiciário é comum a crítica acerca das limitações de ordem jurídicofinanceira exteriorizadas nas normas que dispõem sobre o orçamento público, sob alegação que aos poderes públicos cabe no âmbito da criação e execução orçamentária, determinar as prioridades e a destinação dos recursos públicos na gestão econômica e financeira do Estado.

Isto porque o orçamento além de promover as prestações relativas aos direitos sociais, cabe fixar a receita tributária e patrimonial, determinar a redistribuição de rendas, bem, como promover o desenvolvimento econômico e equilibrar a econômica, através do equilíbrio entre as receitas, despesas e investimentos nos planos anuais ou plurianuais em realização a outros bens e valores sociais (TORRES, 2008, p. 172).

Assim, caberia dentro da partilha de competências constitucionais ao Poder Legislativo a atribuição de definir as prioridades dentre as múltiplas demandas existentes em um contexto de carência de recursos públicos, em razão da legitimidade e responsabilidade advinda do processo majoritário, bem como do melhor conhecimento das receitas disponíveis e das necessidades sociais.

\footnotetext{
7 "What test must a government meet to be legitimate? We cannot say that it is not legitimate unless it is perfectly just: that would be too strong a requirement because no existing government is perfectly just. Many political philosophers have suggested that legitimacy depends not on justice but on consent." e "A legitimate government must treat all those over whom it claims dominion not just with a measure of concern but with equal concern. I mean that it must act as if the impact of its policies on the life of any citizen is equally important." (DWORKIN, 2006, p.95).
} 
Inexistindo previsão orçamentária ou sendo esta insuficiente para a concretização do direito social, não caberia ao Poder Judiciário ordenar a alocação ou sequestro de verbas necessárias a realização da prestação, ignorando as escolhas difíceis realizadas em um contexto de escassez de recurso e de multiplicidade de demandas, em violação as competências atribuídas pela Constituição. (TORRES, 2006, p. 783-785).

Todavia, já foi visto que as normas definidoras dos direitos sociais, vinculam os poderes constituídos em diferentes graus ou medidas, de forma que, embora não seja possível determinar como ocorrerá a realização dos bens e interesses sociais, não torna a margem de livre decisão dos poderes públicos ilimitada, quanto à opção de efetivá-los. (FRASCATI, 2008, p. 102-105)

Condicionar a realização dos bens e interesses sociais à decisão política orçamentária importaria em ignorar a eficácia vinculativa de suas normas definidoras, submetendo a força normativa da Constituição à decisão dos poderes constituídos permitindo que frustrem a efetividade de seus preceitos com a não alocação dos recursos necessários a sua fruição sob alegação de exercício da conformação legislativa dos preceitos constitucionais.

Em outro vértice, se na dimensão do Estado-Orçamentário, há a necessidade da gestão dos recursos estatais, voltada à realização dos preceitos constitucionais no equilíbrio entre despesas e receitas públicas, tal alegada indisponibilidade financeira demonstra além de violação a proteção dos direitos sociais as próprias normas de planejamento e execução orçamentária.

Não cabe o Estado utilizar de sua própria torpeza para furtar-se da obrigação de efetivar o direito social. Ao contrário, a alegação da insuficiência de recursos para a efetivação destes direitos, deve ser demonstrada por meio da indicação do planejamento, dotação orçamentária e aplicação dos recursos que torne inviável a realização do núcleo não essencial. (VAZ, 2008, p. 27 e 36).

Ademais, a reserva do possível não pode expressar exclusivamente a indisponibilidade financeira, pois uma vez que a captação de recursos públicos é realizada de forma permanente pelo Estado através do exercício do poder de tributar há permanente possibilidade de garantia dos direitos fundamentais sociais, seja através da abertura de créditos suplementares ou da previsão no exercício financeiro seguinte.

O que frusta a realização dos direitos fundamentais sociais não é a falta de recurso, mas a opção política de não alocar verbas destinada às prestações relativas aquele direito, sendo o argumento da exaustação orçamentária utilizado para encobrir as escolhas trágicas, que na prática são decisões políticas que excluíram a tutela de determinado direito. (GALDINO, 2002, p. 212215).

Por isto alguns autores sustentam que reserva do possível abrange não apenas a limitação financeiro da concretização do direito fundamental, mas a razoabilidade da prestação exigida e a universalização da decisão (SARMENTO, 2008, p. 572) e se diferencia da reserva da concordância prática para avaliar prestações igualmente eficazes, com resultados quase idênticos e menor custo (BARROSO, 2009, p. 41).

Sustentar que os direitos fundamentais sociais se sujeitam a discricionariedade ou conformação dos poderes públicos - definindo se devem ser colocados ou não a disposição da sociedade - permite que o Poder Público disponha livremente da maior parte do orçamento é violar as próprias regras do jogo democrático, uma vez que, para participar da deliberação pública é necessária ao cidadão a fruição mínima dos direitos fundamentais.

Parte da doutrina considera que o conteúdo essencial dos direitos sociais, enquanto identificável com o mínimo existencial, não se sujeita, ao âmbito da esfera de discricionariedade ou conformação dos poderes públicos ou a reserva do possível, sendo plenamente garantido pela Jurisdição independente das reservas orçamentárias. (TORRES, 2008, p. 80, 95, 105 e 54) (MIRANDA, 1998, p. 349) e (GOUVÊA, 2003, p. 401).

Porém, se por um lado inexiste campo de escolha livre nas escolhas orçamentárias, não necessariamente significa que o Poder Judiciário deve ignorar a existência de previsão 
orçamentária na realização dos direitos sociais. As alocações orçamentárias não correspondem limites insuperáveis ao controle judicial, porém, devem ser tidas no processo cognitivo pelo juiz. (SARMENTO, 2008, p. 573-574).

$\mathrm{Na}$ busca do equacionamento entre estes legítimos vetores - o economicamente viável e o socialmente almejado - a concretização dos direitos sociais pelo Poder Judiciário não pode se subsumir ao parâmetro da reserva do possível para negar a realização da prestação social, mas apenas exprimir a necessidade da prestação ser razoavelmente exigível perante a possibilidade social algo já fixado pelo Supremo Tribunal Federal:

“A realização dos direitos econômicos, sociais e culturais - além de caracterizar-se pela gradualidade de seu processo de concretização depende, em grande medida, de um inescapável vínculo financeiro subordinado às possibilidades orçamentárias do Estado, de tal modo que, comprovada, objetivamente, a incapacidade econômicofinanceira da pessoa estatal, desta não se poderá razoavelmente exigir, considerada a limitação material referida, a imediata efetivação do comando fundado no texto da Carta Política". STF, ADPF 45/DF, j. 29.04.2004, despacho do Min. rel. Celso de Mello.

Coaduna com o imperativo de estabelecimento de distintos momentos, graus e modos de efetivação dos bens e interesses sociais pelos poderes públicos, diante da necessidade de promoção de outros direitos fundamentais insertos nas disponibilidades de recursos financeiros do Estado, porém, compreendendo que não será possível os poderes públicos se furtarem à realização destes interesses e tão pouco o grau progressivo da sua realização.

Isto não importa, na banalização da escassez dos recursos públicos, reconduzindo a equivocada concepção de que os direitos sociais apenas vinculam os poderes públicos diante das possibilidades econômicas (LIMA JUNIOR, 2001, p. 111), porque mesmo diante das restrições de recursos financeiros, subsiste o dever de realização progressiva do conjunto de prestações indispensáveis a sua fruição.

\section{CONCLUSÃO}

Embora possa se reconhecer que há dificuldades de se estabelecer testes de legitimidade e de progressividade absolutos para verificação do orçamento, é preciso impor limites para as escolhas de gastos públicos, uma vez que deve-se afastar a perspectiva clássica de que estes podem ser definidos ao bel-prazer do administrador público. Pesquisas na seara jurídica, econômica e sociológica devem ser realizadas e desenvolvidas com o objetivo de assegurar uma análise que seja capaz de ao menos extirpar do orçamento gastos regressivos.

Conclui-se, ainda, que na construção do orçamento público, não basta mais a análise meramente técnica entre obtenção de recursos e gasto público, mas deve-se considerar sua construção dentro de um sistema deontológico orientado pela Constituição Federal e direcionado à justiça social. Tal construção jurídica, ainda que alimentada por dados econômicos e sociológicos, podem ser objeto de controle judicial.

Os gastos públicos não só podem, mas devem ser utilizados como meio para compensar o caráter regressivo dos tributos, diante da realidade brasileira de distribuição da carga de tributos e benefícios sociais. Gastos públicos, seja por meio da concessão de benefícios físcais ou da distribuição de recursos públicos, dotados de regressividade, ou seja, gastos que, apropriados por parcela favorecida da sociedade, reforçam a regressividade existente no sistema tributário, atuam contra o objetivo constitucional de construção de uma sociedade justa, devendo, portanto, serem considerados inconstitucionais. 
Neste sentido, embora não possa se sustentar um dever de realização plena dos direitos fundamentais sociais, que devem ser realizados em seu núcleo essencial, todavia, pode se afirmar que o orçamento enquanto peça financeira que programa os dispêndios para a concretização dos bens e valores constitucionais deve ser progressivo na busca pela ampliação da sua respectiva realização.

\section{REFERÊNCIAS}

ABRAMOVICH, Victor; COURTIS, Christian. Apuntes sobre la exigibilidad judicial de los derechos sociales. In: SARLET, Ingo Wolfgang (org.). Direitos fundamentais sociais: estudos de direito constitucional, internacional e comparado. Rio de Janeiro: Renovar, 2003.

ASSONI FILHO, Sérgio. Controle de Constitucionalidade da Lei Orçamentária. In: Orçamentos Públicos e Direito Financeiro. São Paulo: Revista dos Tribunais, 2011.

BALEEIRO, Aliomar. Limitações constitucionais ao poder de tributar. $8^{\circ}$ ed. atualizada por Misabel Abreu Machado Derzi. Rio de Janeiro: Forense, 2010.

BALEEIRO, Aliomar. Uma introdução à ciência das finanças. $18^{\mathrm{a}}$ ed. rev. e atualizada por Hugo de Brito Machado Segundo. Rio de Janeiro: Forense, 2012.

BARROS, Ricardo P; FOGUEL, Miguel, N. Focalização dos Gastos Públicos Sociais em Educação e Erradicação da Pobreza no Brasil. Revista Em Aberto. Brasília, v. 18, n.74, 2001.

BARROSO, Luís Roberto. O direito constitucional e a efetividade de suas normas. Limites e possibilidades da Constituição brasileira. 7. ed. Rio de Janeiro: Renovar, 2003.

2006. Interpretação e aplicação da Constituição. 6. ed. Rio de Janeiro: saraiva,

. Da falta de efetividade à judicialização excessiva: direito à saúde, fornecimento gratuito de medicamentos e parâmetros para a atuação judicial. Revista de Direito Social. ano 9. n. 34. página. Cidade: Editora, abr.-jun. 2009.

BIDERMAN, Ciro; AVARTE, Paulo (Organizadores). Economia do Setor Público no Brasil. Rio de Janeiro: Elsevier, 2004.

BOBBIO, Noberto. A era dos direitos. 9. ed. Rio de Janeiro: Elsevier, 2004.

BRASIL, CONGRESSO NACIONAL. Lei Complementar 101. Lei de Responsabilidade Fiscal. Brasília: Congresso Nacional, 2000.

BRASIL, Presidência a República. Observatório da Equidade. Indicadores de Iniquidade do Sistema Tributário Nacional. Brasília: Presidência da República, Conselho de Desenvolvimento Econômico e Social - CDES, $2^{\text {a }}$ ed. 2011.

BRASIL, SUPREMO TRIBUNAL FEDERAL. Ação Direta de Inconstitucionalidade n. 1.640-7. Relator Ministro Sidney Sanches. Brasília: STF, 1998. 
BRASIL, SUPREMO TRIBUNAL FEDERAL. Ação Direta de Inconstitucionalidade n.2925-8. Relator Ministro Marco Aurélio. Brasília: STF, 2003.

BREYNER, Frederico Menezes. Benefícios Fiscais e Regressividade Tributária. In: DERZI, Misabel A. M.; MELO; João Paulo F. de A. Justiça Fiscal. Belo Horizonte: Del Rey, 2016.

BONAVIDES, Paulo. Curso de direito constitucional. 13. ed. São Paulo: Malheiros, 2003.

CANOTILHO, José Joaquim Gomes. Constituição dirigente e vinculação do legislador. Coimbra: Coimbra Ed., 1982.

CARVAlHO, Paulo de Barros. Curso de Direito Tributário. 19ª Edição. São Paulo: Saraiva, 2007.

CASTRO, Fábio A. Imposto de renda da pessoa física: comparações internacionais, medidas de progressividade e redistribuição. Dissertação de Mestrado. Departamento Economia da Universidade de Brasília. Brasília. 2014.

CASTRO, Marcus F. Direito, Tributação e Economia no Brasil: Aportes da Análise Jurídica da Política Econômica. Revista da PGFN, v. 1, p. 23-51, 2011.

DERIZ, Misabel Abreu Machado. Atualizações. In: BALEEIRO, Aliomar. Limitações constitucionais ao poder de tributar. $8^{\circ}$ ed. Rio de Janeiro: Forense, 2010.

DERZI, Misabel A. M. Guerra Fiscal, Bolsa Família e Silêncio (relações, efeitos e regressividade). In: Revista Jurídica da Presidência. Brasília: Presidência da República. vol. 16, n.108, fev/mai 2014.

DWORKIN, Ronald. Is democracy possible here? Principles for a new political debate. Princeton-Oxford: Princeton University Press, 2006.

FERRAZ, Luciano; GODOI, Marciano S.; SPAGNOL, Werther B. Curso de Direito Financeiro e Tributário. Belo Horizonte: Fórum, 2014.

FRASCATI, Jacqueline Sophie P. G. Força jurídica dos direitos sociais, econômicos e culturais. Revista de Direito Constitucional e Internacional. vol. 63. p. 81. São Paulo: Ed. RT, abr. 2008.

GALDINO, Flávio. O custo dos direitos. In: TORRES, Ricardo Lobo. Legitimação dos direitos humanos. Rio de Janeiro: Renovar, 2002.

GASSEN, Valcir (Org. e autor). Matriz tributária brasileira: uma perspectiva para pensar o Estado, a Constituição e o Direito Tributário. In: Equidade e eficiência da matriz tributária brasileira: diálogos sobre Estado, Constituição e Direito Tributário. Brasília: Consulex, 2012.

GASSEN, Valcir. Direito tributário: pressupostos e classificações dos tributos. Brasília: 2009. Mimeo. 
GIAMBIAGI, Fábio; ALÉM, Ana C. Finanças Públicas: teoria e prática no Brasil. Rio de Janeiro: Elsevier. 2011.

GOUVÊA, Marcos Maselli. O controle judicial das omissões administrativas: novas perspectivas de implantação dos direitos prestacionais. Rio de Janeiro: Forense, 2003.

HESSE, Konrad. A força normativa da Constituição. Porto Alegre: Sergio Antonio Fabris Ed., 1991.

HOLMES, Stephen; SUNSTEIN, Cass R. The cost of rights: why liberty depends on taxes. New York: Norton \& Company, 1999.

LEONETTI, Carlos A. O imposto sobre a renda como instrumento de justiça social no Brasil. Barueri, SP: Manole, 2003.

LIMA JUNIOR, Jayme Benvenuto. Os direitos humanos econômicos, sociais e culturais. Rio de Janeiro: Renovar, 2001.

MACHADO SEGUNDO, Hugo de Brito. Atualizações In: BALEEIRO, Aliomar. Uma introdução à ciência das finanças. 18ª ed. Rio de Janeiro: Forense, 2012.

MEDEIROS, Marcelo. SOUZA, Pedro H. G. F. Gasto Público, Tributos e Desigualdade de Renda no Brasil. Brasília: Instituto de Pesquisa Econômica Aplicada. Texto para Discussão n. 1844. jun, 2013.

MEDEIROS, Marcelo; SOUZA, Pedro H. G. F.; CASTRO, Fábio A. A estabilidade da desigualdade de renda no Brasil, 2006 a 2012: estimativa com dados do imposto de renda e pesquisas domiciliares. Rio de Janeiro: Ciência \& Saúde Coletiva. v. 20, n. 4, 2015.

MIRANDA, Jorge. Manual de direito constitucional. Direitos fundamentais. Tomo IV. 2. ed. Coimbra: Almedina, 1998.

NAGATA, Bruno, M. A Limitação da discricionariedade em matéria orçamentária pelos princípios da legalidade, legitimidade e economicidade. In: Orçamentos Públicos e Direito Financeiro. São Paulo: Revista dos Tribunais, 2011.

NAGEL, Thomas; MURPHY, Liam. O mito da propriedade: os impostos e a justiça. São Paulo: Martins Fontes, 2005.

OLIVEIRA, Regis F. Curso de direito financeiro. São Paulo: Editora Revista dos Tribunais, 2013.

PASUKANIS, Eugeny Bronislanovich. A teoria geral do direito e o marxismo. Rio de Janeiro: Renovar, 1989. 
PIOSEVAN, Flávia. Direitos humanos e o direito constitucional internacional. 3. ed. atual. São Paulo: Max Limonad, 1997.

ROCHA, Fabiana; MATTOS, Enlinson. Distribuição de Renda e Gasto Público: uma análise de eficiência para os estados brasileiros. Temas de Economia Aplicada. São Paulo: Informações FIPE, jun. 2011.

ROSA JR, Luiz E. F. Manual de Direito Financeiro e Direito Tributário. Rio de Janeiro: Renovar, 2007.

SARLET, Ingo Wolfgang. A eficácia dos direitos fundamentais. 4. ed. rev., atual e ampl. Porto Alegre: Livraria do Advogado, 2004.

SARMENTO, Daniel. A proteção judicial dos direitos sociais: alguns parâmetros éticojurídicos. In: ; SOUZA NETO, Cláudio Pereira de (orgs.). Direitos sociais: fundamentos, judicialização e direitos sociais em espécie. Rio de Janeiro: Lumen Juris, 2008.

SCAFF, Fernando F. A efetivação dos direitos sociais no Brasil. Garantias constitucionais de financiamento e judicialização. In: A eficácia dos direitos sociais. São Paulo: Quartier Latin, 2010 .

SCAFF, Fernando F. Reserva do possível, mínimo existencial e direitos humanos. João Pessoa: Verba Juris, v.4, n.4. 2005.

SOUZA NETO, Cláudio Pereira de. A justiciabilidade dos direitos sociais: críticas e parâmetros. In: ___ SARMENTO, Daniel. Direitos sociais: fundamentos, judicialização e direitos sociais em espécie. Rio de Janeiro: Lumen Juris, 2008.

SPAGNOL, Werther B. Da tributação e sua destinação. Belo Horizonte: Del Rey, 1994.

TORRES, Ricardo Lobo. Curso de Direito Financeiro e Tributário. Rio de Janeiro: Renovar. 2013.

Renovar, v.1, 2009.

. Tratado de Direito Constitucional Financeiro e Tributário. Rio de Janeiro: . O direito ao mínimo existencial. Rio de Janeiro: Renovar, 2009.

TORRES, Silvia Faber. Direitos sociais prestacionais, reserva do possível e ponderação: breves considerações e críticas. In: SARMENTO, Daniel; GALDINO, Flávio. Direitos fundamentais: estudos em homenagem ao professor Ricardo Lobo Torres. Rio de Janeiro: Renovar, 2006.

VAZ, Anderson Rosa. A cláusula da reserva do financeiramente possível como instrumento de efetivação planejada dos direitos humanos, econômicos, sociais e culturais. RDCI 66/27 e 36. 